\title{
Severe slug mitigation in an S-shape pipeline-riser system by an injectable venturi
}

\author{
Joseph Inok a, Liyun Lao ${ }^{\text {a, }}$,, Yi Cao ${ }^{\text {b }}$, James Whidborne ${ }^{\text {c }}$ \\ a Department of Energy and Power, Cranfield University, United Kingdom \\ ${ }^{b}$ College of Chemical and Biological Engineering, Zhejiang University, Hangzhou, China \\ ${ }^{c}$ Dynamics Simulation and Control Group, Cranfield University, United Kingdom \\ * Corresponding author \\ Email address: l.lao@cranfield.ac.uk
}

\begin{abstract}
Severe slugging is a cyclic flow regime that causes pressure, flow and temperature oscillations which leads to an intermittent delivery of liquid (oil and water) and gas to processing facilities during hydrocarbon extraction and transportation. These oscillations can cause separator flooding, production reduction, platform trips and plant shutdown. This paper presents a novel method for severe slug mitigation in a pipeline-riser system which use an injectable venturi coupled to the pipeline-riser system upstream of the topside test separator for severe slug mitigation. Injectable venturi is a venturi tube that has an opening at its throat and a pipe inclined at $45^{\circ}$ is inserted into this opening. Gas is injected through the pipe counter to the flow coming from upstream of the injectable venturi to choke the working fluid passing through the throat of the injectable venturi. Flow regimes maps, stability maps, severe slug envelopes and Hopf bifurcation maps were generated and used to demonstrate the performance of the injectable venturi in mitigating severe slugging in a pipeline-riser system. A similar experiment was conducted with the injectable venturi with no gas injection and the plain riser (without the injectable venturi coupled). The results from the experiment show that with the injectable venturi coupled to the pipeline-riser system, severe slugging was mitigated, the severity of severe slugging was reduced, the operating region of severe slugging (severe slug envelop) was reduced and stability was achieved at a larger valve opening. Practically, these results imply that oil and gas production can proceed more smoothly, thus, enhancing flow assurance. The injectable venturi with gas injection gave a better performance than with no gas injection. Thus, the effectiveness of the injectable venturi is not due to the venturi itself, but due to gas injection at the throat of the venturi.
\end{abstract}

Keywords: Injectable venturi; Severe slug mitigation; Bifurcation map, Severe slug envelop; Flow assurance; Stability study

\section{Introduction}

The exploitation and uninterrupted transportation of hydrocarbon are of utmost importance to the oil and gas industry. With the depletion of conventional oil reserves, oil and gas activities have shifted to deep offshore. Most of these oil wells are only economically viable if they are tied back to the existing platform in order to reduce capital expenditure (CAPEX). Thus, marginal fields once deemed uneconomical to explore, can now be economically produced through a multiphase flow pipeline. The trend towards more satellite wells has led to longer multiphase transport pipelines from the well clusters and wellhead platforms into the production platforms. However, a few problems may arise during the transportation process. One of the major challenges is a phenomenon called severe slugging.

Severe slugging is a cyclic flow regime that causes pressure, flow and temperature oscillations which leads to intermittent delivery of liquid (oil and water) and gas to processing facilities during hydrocarbon extraction and transportation. These oscillations can cause separator flooding, production reduction, platform trips and plant 
shutdown. The large and rapid variation in flow reduces the average flow output which could be as large as $50 \%$. This relative inefficiency results in substantial profit losses which may put a production company out of business (Di Meglio et al., 2010). Therefore, there is a need to handle severe slugs in a more efficient way. Thus, it is important to develop effective and efficient methods to eliminate or prevent such flow behaviour.

Severe slugging in an offshore field was first reported by Yocum (1973) where he identified the threat of severe slugging to production facilities and the different approaches for severe slug elimination. Typical approaches includes installing flow conditioners (Xing et al., 2013a, 2013b, 2013c; Almeida and Gonçalves, 1999, 2000; Adedigba, et al.,, 2006; Adedigba, 2007), intermittent absorber (Ehinmowo et al., 2016), multiple risers (Kaasa, 1990; Prickaerts et al., 2013), slug catchers (McGuinness and Cooke, 1993), using fixed or permanent choking (Schmidt et al., 1979, 1980; Taitel, 1986; Taitel et al., 1990; Farghaly, 1987; Jansen et al., 1996) and using different intrusive devices (Schrama and Fernandes, 2005; Brasjen et al., 2013). Xing et al. (2013a, 2013b) carried out experimental studies and numerical study (Xing et al., 2013c) to investigate the effects of the wavy pipe on the flow behaviour in a pipeline-riser system and to verify its effectiveness in severe slugging mitigation. Almeida and Gonçalves, $(1999,2000)$ proposed and patented a Venturi device which prevented the formation of severe slugging. Adedigba et al. (2006) and Adedigba (2007) used a helical pipe to converted stratified flow into bubble flow, hence, mitigating severe slugging. Ehinmowo et al. (2016) proposed the use of an intermittent absorber for severe slug attenuation at large valve opening. Kaasa (1990) used a sub-sea slug catcher with T-splitter to distribute gas and liquid into two risers to prevent or mitigate severe slugging. Also, Prickaerts et al. (2013) used two risers with the aid of a non-symmetric branch T-splitter for severe slug mitigation. McGuinness and Cooke (1993) used slug catcher at the top of the well for severe slug mitigation. The idea was to prevent having multiphase flow completely from the transportation line. However, these methods have their peculiar disadvantages; slug catcher and flow conditioning require very expensive design changes. Pipeline choking is one of the effective approaches to eliminate severe slugging in oil and gas production systems. Nevertheless, due to the restriction caused by choking, oil production could be significantly reduced by fixed choking (Havre, Stornes and Stray, 2000). Some automatic control strategies have been reported for severe slug mitigation (Havre et al., 2000; Havre and Dalsmo, 2001; Siahaan et al., 2005; Di Meglio et al., 2012; Stasiak et al., 2012; Ogazi et al., 2009, 2010; Henriot et al., 1999; Godhavn et al., 2005; Storkaas and Skogestad, 2004). However, it is difficult to use a choke valve to eliminate severe slugging without reducing the production rate. Consequently, a robust and efficient slug control solution is needed that will be robust enough to address this flow assurance challenge adequately.

Gas injection or external gas lifting was first proposed by Yocum (1973), Schmidt et al. (1979, 1985) also considered it in their work. Hill $(1989,1990)$ reported from his study that gas lift helps in the attenuation of slugging; enables more continuous production, and also helps to ensure smooth start-up of a pipe system that has been shut down. However, its major drawback is the large amount of gas required to achieve stabilisation. In addition, the additional cost to CAPEX due to compressor cost, and the lack of injection capabilities have caused some operators to avoid this method. Nevertheless, the recent changes in the oil and gas sector have made gas injection favourable. One of them is the "No flaring" environmental policy which enforces the availability of gas compression facilities to all new development for export or re-injection of gas.

Schmidt et al. (1985) and McGuinness and Cooke (1993) stated that one of the necessary condition for severe slugging to occur is that flow in the riser must be unstable. Consequently, if a technique can stabilise the flow in 
the riser, severe slugging can be eliminated. A novel mitigation technique for severe slugging in pipeline-riser systems is presented in this paper. This study describes the use of an injectable venturi coupled to the S-shape pipeline-riser system upstream of the topside test separator for severe slug mitigation. The availability of compressors or gas for injection would not be a challenge due to the No flaring policy. Several experiments were conducted on a 2" pipeline-riser system with the plain riser and with the injectable venturi with and with no gas injection coupled. The injectable venturi with no gas injection (venturi) was used to compare the performance of the injectable venturi in severe slug mitigation in order to be sure that the enhancement in the performance of the injectable venturi over the venturi is entirely due to the gas injection and not the venturi. The stabilising and attenuation performance of this concept on severe slugging is shown using, flow regime maps, stability maps and severe slug envelopes.

This paper is structured as follows: Section 2 presents the design of the injectable venturi, Section 3 presents the experimental facility and procedure. Section 4 presents the results and discusses the different observations from the results, and Section 5 presents the conclusion of the study.

\section{Design of injectable Venturi}

Venturi here refers to a tube with convergent, throat, and divergent section that are generally used for measurement and flow regulation purposes. The Venturi effect is the reduction in fluid pressure which occurs when a fluid flows through a narrow constricted section of a pipe. The reduction in pressure results in an increase in velocity which agrees with Bernoulli's principle. It utilizes both the principle of continuity as well as the principle of conservation of energy.

The gradual flowing area contraction (nozzle) followed by a gradual flowing area expansion (diffuser) of the venturi helps in accelerating fluids and may account for the low loss of energy in a venturi. Generally, a venturi produces less permanent pressure losses and high-pressure recovery due to the diffuser when compared to orifice or nozzle. Thus, it saves energy.

An injectable venturi is a venturi tube that has an opening at its throat and a pipe inclined at $45^{\circ}$ is inserted into this opening. Thus, gas is injected counter to the flow coming from upstream of the injectable venturi to choke the working fluid passing through the throat of the injectable venturi. Basically, it operates as a venturi and enjoys the benefits associated with a venturi. However, gas is injected to further reduce the size of the throat in order to further stabilise the flow. Fig. 1 shows a photograph of the tested injectable venturi installed in the pipeline. 


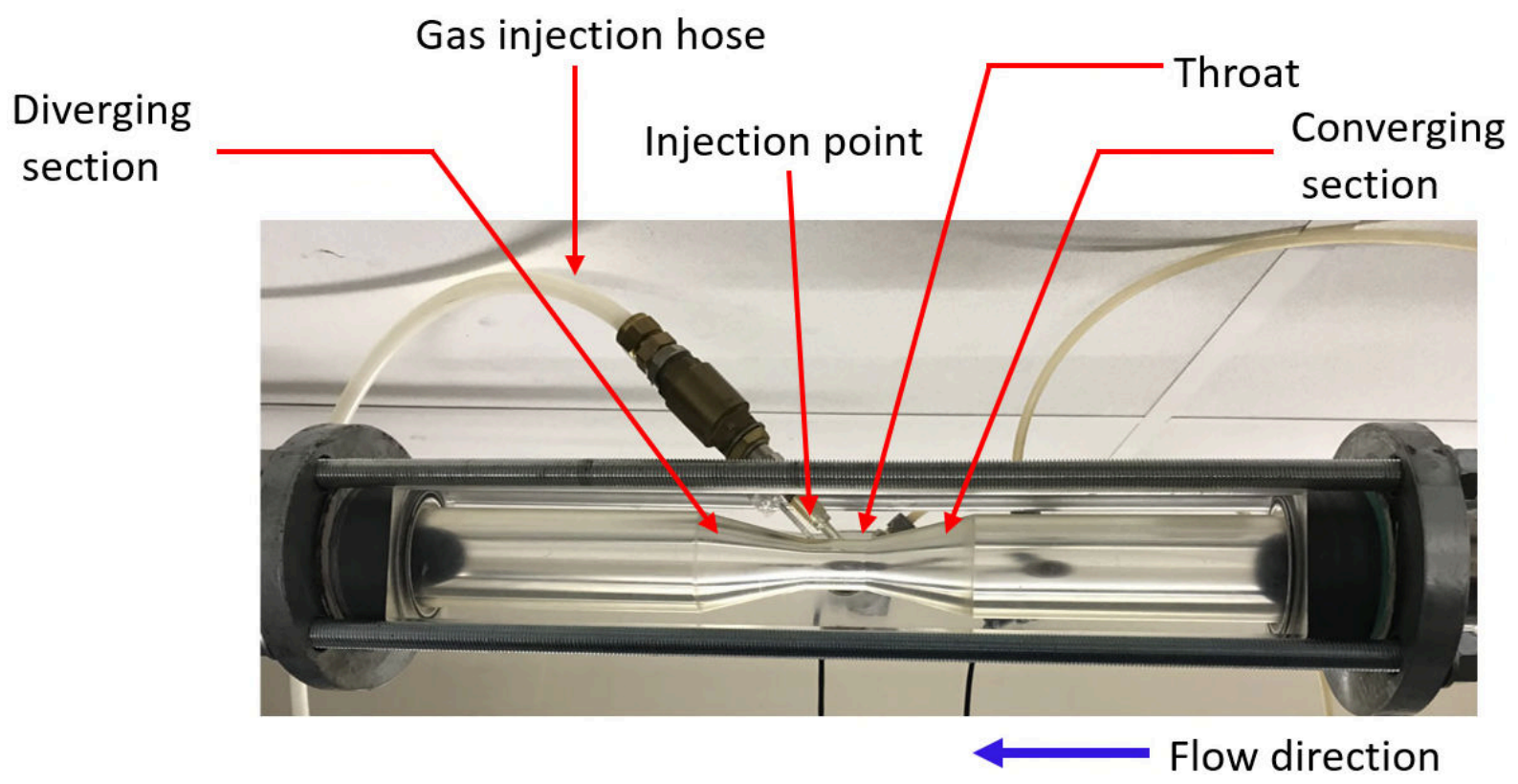

Fig. 1. Injectable venturi

This technique is applied to regulate the size of the throat of a normal venturi in order to be able to stabilise a wider range of unstable flow regimes that may have required a new venturi design. Thus, injectable venturi is more robust and offers more degrees of freedom than the conventional venturi. The idea of using the injectable venturi in this study was initiated with the belief that the venturi principle could be enhanced and used to modify the flow characteristics of severe slugging in order to stabilise the flow in the riser, thus, eliminate severe slugging. 


\section{Experimental facility and procedure}

\subsection{Experimental flow loops}

The experiment was conducted at Cranfield University three-phase (air, oil and water) test facility shown in Figure 2. This fully automated high-pressure test facility is designed to supply a controlled and measured range of multiphase fluid (oil, water and air mixture). The experiments were conducted with two flow loops: the primary loop (main test loop) and the secondary (gas injection loop).

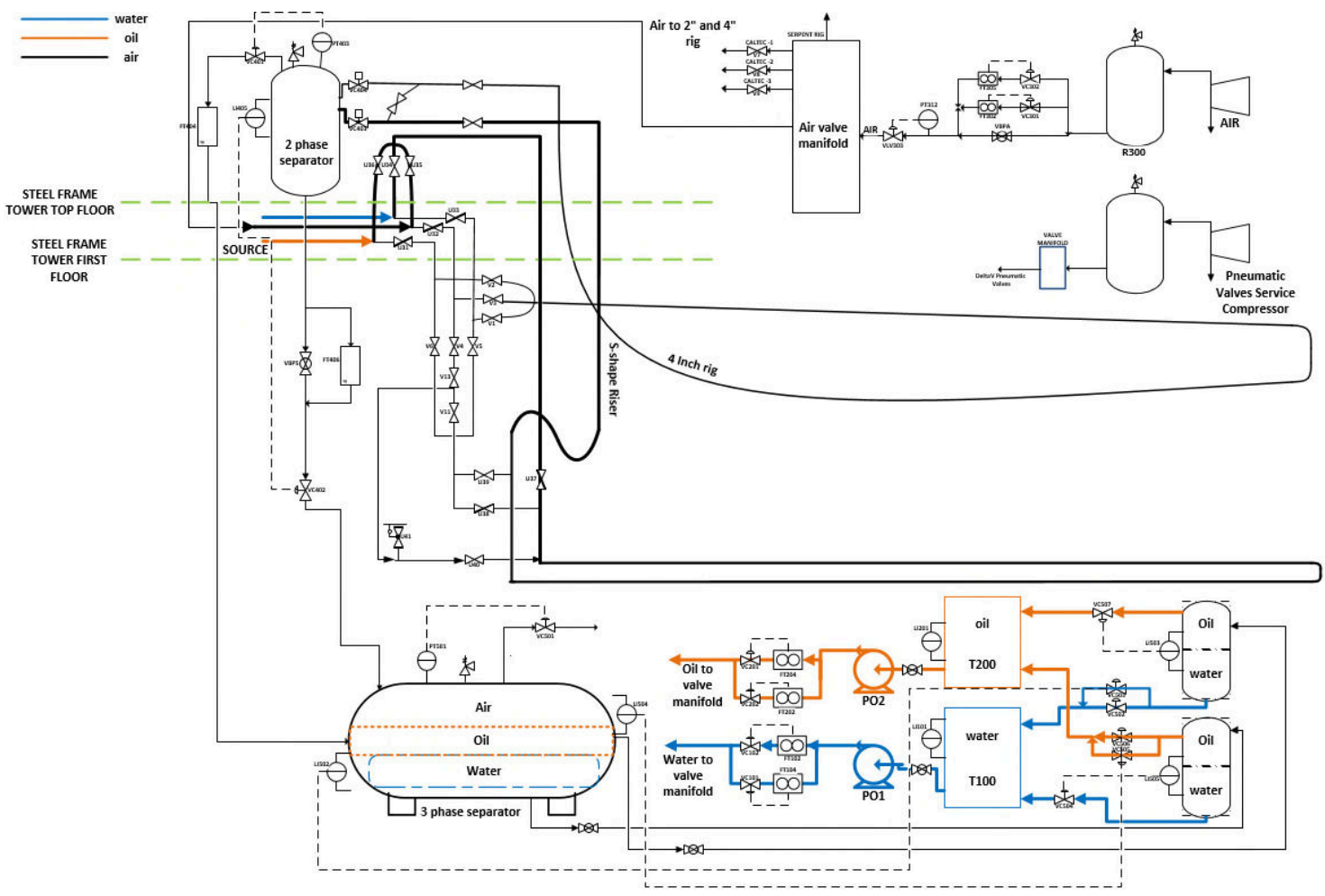

Fig. 2. Schematic of the Three-Phase Test Facility: Overall Structure

\subsubsection{Primary loop}

The main test loop consists of three parts: a $40 \mathrm{~m}$ horizontal pipeline to ensure full development of multiphase flow; an S-shaped riser with total height of $11.75 \mathrm{~m}$ and upper limb, lower limb and downcomer of $6.28\left(45^{\circ}\right) \mathrm{m}$, $4.69\left(90^{\circ}\right) \mathrm{m}$ and $0.8\left(45^{\circ}\right) \mathrm{m}$ in height respectively; and a $5.2 \mathrm{~m}$ horizontal topside section. This configuration 
was used throughout the experiments; however, an injectable venturi was incorporated upstream of a choke valve when we needed to study the effects of injectable venturi on the system. The injected gas supply from the secondary loop was cut off for venturi experiments. Thus, the hole in the venturi throat was sealed and the device operated as a normal venturi. Fig. 3 shows a simplified pipeline-riser system with the injectable venturi installed. The inner diameter of the choke is the same as for the pipeline $(54.8 \mathrm{~mm})$; thus, when the valve is fully opened, the pressure drop over the choke can be ignored. All pipes of the 2" test section have an internal diameter of 54.8 $\mathrm{mm}$ and are made up of stainless steel, except the riser which is made up of transparent PVC pipe and the $0.4 \mathrm{~m}$ high transparent Perspex segment located at the riser base for visual observations of flow in the riser.

Air and water were used as working fluids in this study; they are supplied and metered at the supply and metering section. The test matrix for the experiments ranged from $5 \mathrm{~m}^{3} / \mathrm{hr}$ to $300 \mathrm{~m}^{3} / \mathrm{hr}(0.35 \mathrm{~m} / \mathrm{s}-39.03 \mathrm{~m} / \mathrm{s}$ superficial velocities) for air and $0.1 \mathrm{~kg} / \mathrm{s}$ to $5 \mathrm{~kg} / \mathrm{s}(0.05 \mathrm{~m} / \mathrm{s}-2.48 \mathrm{~m} / \mathrm{s}$ superficial velocities $)$ for water. Air is supplied from a bank of two compressors connected in parallel. When both compressors are run in parallel, a maximum air flow rate of $1410 \mathrm{~m} 3 / \mathrm{hr} F A D$ at 7 barg can be supplied. The air from the two compressors is accumulated in an $8 \mathrm{~m}^{3}$ capacity receiver to reduce the pressure fluctuation from the compressor. Air from the receiver passes through a bank of three filters (coarse, medium and fine) and then through a cooler where debris and condensates (present in the air) are stripped from the air before it goes into the flow meters.

Water is supplied from a $12.5 \mathrm{~m}^{3}$ capacity water tank, which is a multistage Grundfos CR90-5 pump with a duty of $100 \mathrm{~m}^{3} / \mathrm{hr}$ at $10 \mathrm{barg}$. Speed control is achieved using frequency variable inverters. The pumps are operated remotely using DeltaV.

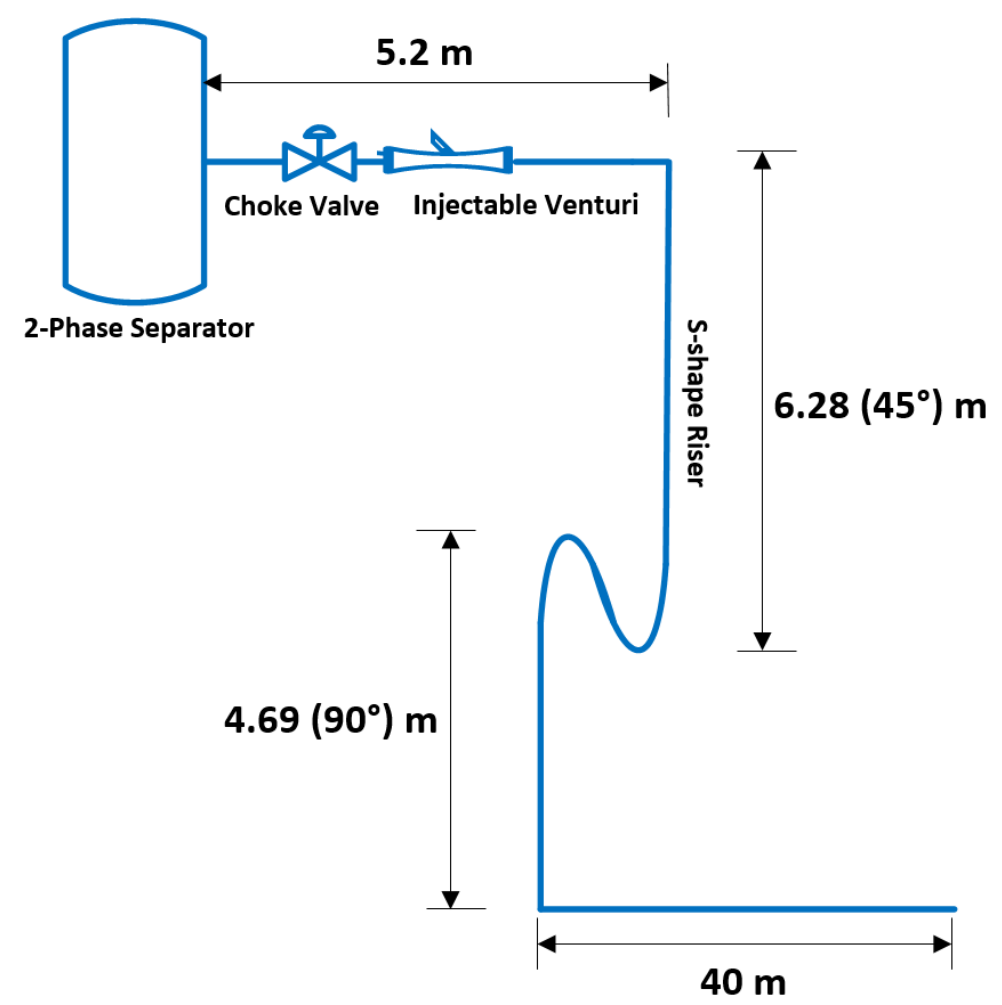

Fig. 3. A simplified pipeline-riser system with injectable venturi installed 


\subsubsection{Secondary loop}

The gas injection flow loop consists of a stainless steel horizontal pipeline, a flexible tube, pressure regulator, pressure control valve, flow transmitter, pressure gauge, two ball valves and two non- return valves. The horizontal pipeline is $2 \mathrm{~m}$ long and the flexible tube has a total height of $13 \mathrm{~m}$ and they are both $1 / 2 "$.

The loop uses the same air supply as the test loop, however, the air is regulated by the pressure regulator and the required amount of gas injected into the system is controlled by the pressure control valve (PCV). The PCV is controlled remotely by a LabVIEW program designed for this purpose and the gas was injected at $50 \mathrm{~m}^{3} / \mathrm{hr}$. The flexible pipe is connected to the throat of the venturi at $45^{\circ}$ such that it opposes the flow coming from upstream the injectable venturi to the throat.

\subsection{Instrumentation and data processing}

The test facility is powered and fully controlled by the DeltaV® plant management system, which is a Fieldbus based Supervisory, Control and Data Acquisition (SCADA) system supplied by Emerson Process Management to ensure that the system is monitored, the desired operating conditions are achieved and the required data are recorded.

The flow rates of the air and water are regulated by their respective control valves. The air is metered by a bank of two Rosemount Mass Probar flow meters of $1 / 2 "$ and 1" diameter respectively. The smaller air flow meter measures the lower air flow rate (up to $150 \mathrm{Sm} 3 / \mathrm{h}$ ) while the larger one meters the higher air flow rate up to 4250 $\mathrm{Sm}^{3} / \mathrm{h}$ (subject to compressor capacity). The water flow rate is metered by a 1" Rosemount 8742 Magnetic flow meter (up to 7.36 1/s) and a 3" Foxboro CFT50 Coriolis meter (up to $30 \mathrm{~kg} / \mathrm{s}$ ).

The air from the two-phase topside separator is metered by a 1" Rosemount Vortex flow meter while the water/oil mixture is metered by a 2" Micro Motion Mass flow meter. A by-pass line with a manual valve is installed across the 2 " flow meter to facilitate experiments which require large liquid flow rates. The pressure at the test section was measured by GE Druck PMP 1400 pressure transducers of range 0-6 barg and uncertainty $\pm 0.25 \%$ of full scale. The temperature at the gas metering section was measured by thermocouples of range 0 $100{ }^{\circ} \mathrm{C}$ and uncertainty $\pm 1 \%$ of full scale.

All signals were acquired in the DeltaV Historian database and a high-speed multifunction National Instrument modules NI 9215 at a frequency of $1 \mathrm{~Hz}$ and $100 \mathrm{~Hz}$ respectively, which was sufficient for this study. These modules are housed by the National Instrument chassis NI cDAQ-9172 which transmitted the converted digital signals to the LabVIEW program. The sampling time of the signals was 600 seconds. A LabVIEW-based data acquisition and analysis program was used for data acquisition and processing. The DeltaV SCADA system is used to remotely operate the rig and perform the experimental procedure including pressurising and depressurising the system, control, shut down and data acquisition. 


\subsection{Differential pressure normalisation}

Pressure analysis was used for identifying flow patterns and defining the different stages of severe slugging cycle. Thus, the differential pressure of the entire riser length (riser base to top side) was used to analyze the various flow patterns present in the test matrix. This differential pressure was normalized to make the differential pressure signal results comparable.

Firstly, the static differential pressure of the entire riser length of the empty riser was measured and recorded. Secondly, the riser was filled with water and the static differential pressure recorded. Finally, the riser was emptied and the static differential pressure of the empty riser was recorded again. The average of the two empty static differential pressure $\left(P_{\text {air }, \text { ave }}\right)$ was calculated and subtracted from the static differential pressure value of when the riser was filled with $\left(P_{\text {water }}\right)$ water to give the reference differential pressure $\left(\Delta P_{s, f}\right)$ as:

$$
\Delta P_{s, f}=P_{\text {water }}-P_{\text {air }, \text { ave }}
$$

The reference differential pressure corresponds to the static fluid differential pressure of the riser. The differential pressure for each test point $(\Delta P)$ within the test matrix was recorded at a sampling rate of 100 samples per seconds for a duration of 600 seconds. The dimensionless normalized differential pressure $\Delta P^{*}$ was determined as:

$$
\Delta P^{*}=1-\frac{\Delta P}{\Delta P_{s, f}}
$$

According to Matsui $(1984 ; 1986)$ for flows with negligible acceleration and friction pressure losses, $\Delta P^{*}$ would be indicative of the phase in the measurement section. Thus, the value of this dimensionless normalised parameter would be close to either 0 or 1 if the measurement volume between the two pressure taps were occupied by the liquid phase or gas phase, respectively (Shaban and Tavoularis, 2014). The normalised differential pressures were used to generate probability density function (PDF) and power spectral density (PSD) graphs which were used to identify the various flow regimes objectively.

\subsection{Calculation of PDF and PSD of normalized differential pressure}

PDF is used to specify the probability of a random variable falling within a particular range of values and is defined as:

$$
Y(a \leq x \leq b)=\int_{a}^{b} D(x) d x
$$

where $Y(a \leq x \leq b)$ is the probability that the variable $x$ lies between $a$ and $b$, and $x$ is the normalised differential pressure across the entire riser length $\left(\Delta P^{*}\right)$. 
The PDF was computed in MATLAB program by separating the values of $\Delta P^{*}$ into 500 bins, each having a width of 0.002 , which corresponded to a vector of 500 representative features.

The PSD is a frequency domain characteristic of a time series that is suitable for detecting the frequency components hidden in a stochastic process (Matsumoto and Suzuki, 1984). It can be used to reveal the distinctiveness in the signal of flow regimes present in a multiphase flow (Abbagoni and Yeung, 2016). Fast Fourier transform is used to create the PSD spectrum, which assumes that the process signal (normalised differential pressure) is stationary and ergodic. The PSD function $D_{x}(f)$, of a discrete signal $x(n)$ is defined as the Fourier transform of the autocorrelation sequence $R_{x}(k)$ of the signal (Xie et al., 2004):

$$
D_{x}(f)=\sum_{k=-\alpha}^{\propto} R_{x}(k) e^{-i 2 \pi f / f_{s}}
$$

where $f_{s}$ is the sampling frequency.

For an unlimited amount of data and real-valued continuous data, the autocorrelation sequence can be approximated by a time-average given as (Xie et al., 2004):

$$
R_{x}(K)=\lim _{N \rightarrow \infty} \frac{1}{2 N+1} \sum_{n=-N}^{N} x(n+k) x(n)
$$

The signal was recorded for a finite time interval during the experiment, this may present some distortions to the spectrum. Consequently, a modified form of the PSD, called the Welch method, is adopted. Welch (1967) subdivided the signal sample into small length N-point overlapping segments, applied a window function to each data segment, calculated the periodogram of each of the segments and then averaged the periodograms in order to obtain the estimated power spectrum. Thus, the PSD of the $\Delta P^{*}$ was computed in MATLAB program using Welch's average periodogram method.

The PSD was estimated using a segment length which was computed as the next power of two greater than the number of samples and a Hanning window at $50 \%$ overlap was applied in order to reduce the variance of the estimates.

\section{Results}

\subsection{Flow pattern characterisation in S-shape pipeline-riser system}

The flow pattern in a pipeline-riser system have been classified by several researchers (Montgomery and Yeung, 2002; Li et al., 2017; Tin, 1991; Schmidt et al., 1979, 1980; Park and Nydal, 2014; Matsui, 1984; Malekzadeh et al., 2012; Li et al., 2013; Ye and Guo, 2013; Taitel et al., 1990). The flow patterns were classified 
into ten categories viz.: severe slug type I (SS-I), severe slug type II (SS-II), severe slug type III (SS-III), transitional severe slug type I (SST-I), transitional severe slug type II (SST-II), oscillation flow (OSC), bubble flow, slug flow, churn flow and annular flow. They were additionally broadly categorized as severe slugging, transitional severe slugging and stable flow.

\subsubsection{Severe slugging (SS)}

Severe slugging typically exhibits cyclic behaviour and has been previously identified by several researchers (Tin, 1991; Li et al., 2013; Schmidt et al., 1985; Baliño et al., 2010; Malekzadeh, 2012; Montgomery, 2002). Generally, it is encountered at relatively low gas and liquid superficial velocity and can be described in four stages; the slug formation, slug production, bubble penetration, and gas blowdown and liquid fall-back. In this study, three types of severe slugging were identified in this study: SS-I, SS-II and SS-III.

Severe slug type I (SS-I): This has been identified previously by various researchers as classical severe or severe slugging (Ehinmowo et al., 2016; Tin, 1991; Baliño et al., 2010; Xing et al., 2013a; Schmidt et al., 1985). It exhibits the four-stage cyclic behaviour of severe slugging; the slug formation, slug production, bubble penetration, and gas blowdown and liquid fall-back as shown in Fig.4a. The PDF (Fig.4b) has a two-peak distribution where one peak occurs in the period of slug generation and the other peak in the period of slug production. The pressure impact when gas blowout occurs is manifested as the long tail of the distribution. The PSD (Fig.4c) exhibits two clear peaks, the lower frequency peak is more dominant and has a larger PSD amplitude.

Severe slug type II (SS-II): This occurs when the gas velocity increases such that bubble penetration occurs just when the slug front arrives at the top of the riser. The penetration of gas tends to accelerate the liquid slug into the separator and causes gas blowout. SS-II typically exhibits three stages in each individual cycle as can be seen in Fig.4d. Thus, there is no stable slug production stage as in SS-I since the process of slug formation is followed immediately by bubble penetration. The PDF (Fig.4e) has three-peak distribution with the smallest at lower pressure. The PSD (Fig.4f) has multiple peaks and a major peak with a large PSD amplitude that has a higher and strong dominant frequency than SS-I.

Severe slug type III (SS-III): This manifested at higher flow rates when compared with SS-I. There is continuous gas penetration at the riser base during the slug production stage as can be seen in Fig.4g. This is as a result of the higher friction of the fast-moving liquid carrying gas into the separator. The PDF (Fig.4h) shows one major peak and two other peaks at pressures lower and higher than that of the highest peak. This corresponds to the pressure differences before and after the gas penetration. The PSD (Fig.4i) has a major peak with a strong dominant frequency and two other smaller peaks in the frequency domain. The PSD amplitude of the major peak is larger than that of SS-I and SS-II. 

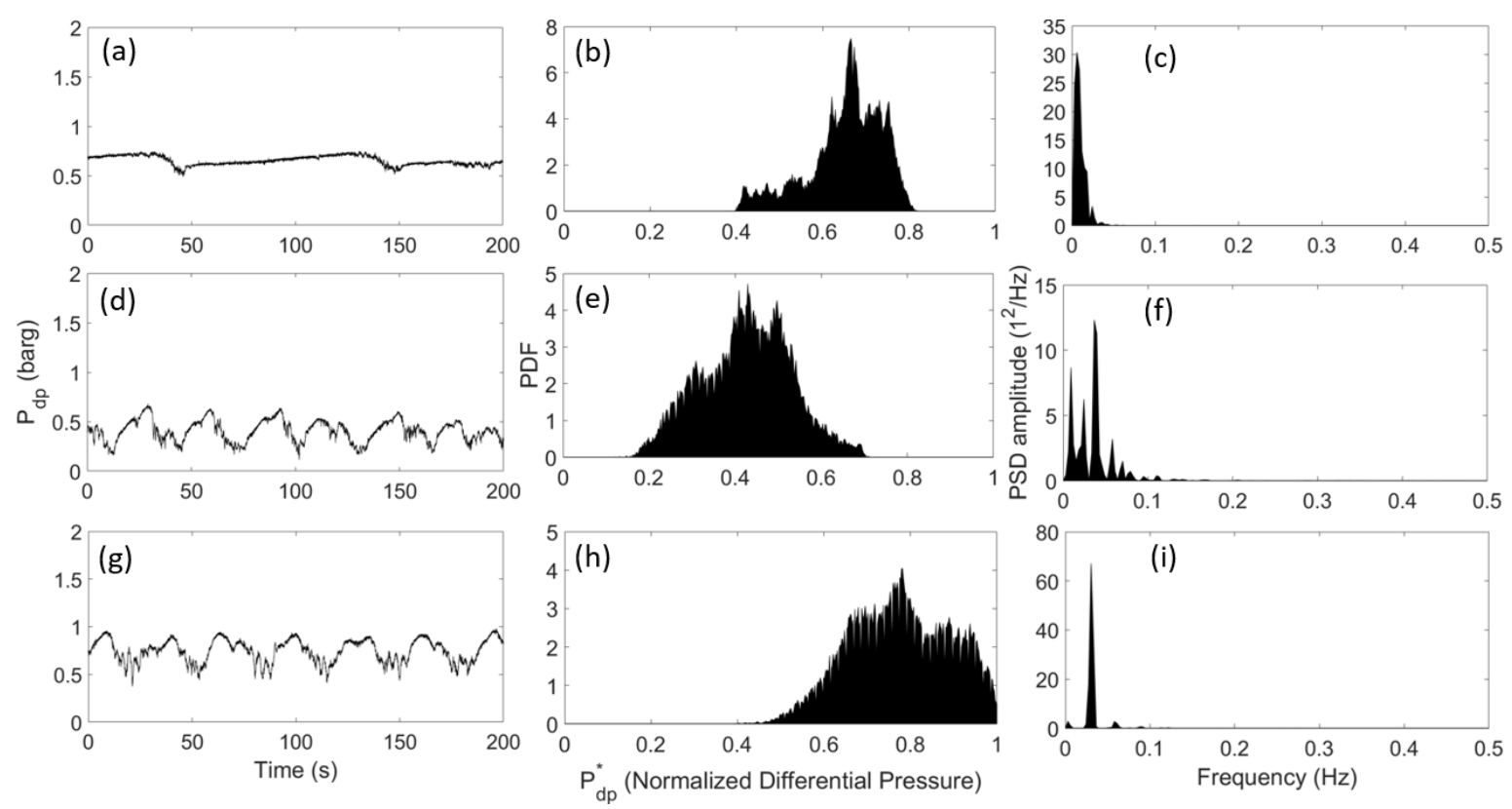

Fig. 4. Differential pressure over the riser (time series), PDF and PSD of the differential pressure over the riser during different types of severe slugging flow (a,b,c) $V_{s l}=0.05 \mathrm{~m} / \mathrm{s}, V_{s g}=0.44 \mathrm{~m} / \mathrm{s}(\mathrm{SS}-\mathrm{I}) ;(\mathrm{d}, \mathrm{e}, \mathrm{f}) V_{s l}=0.25$ $\mathrm{m} / \mathrm{s}, V_{s g}=2.0 \mathrm{~m} / \mathrm{s}(\mathrm{SS}-\mathrm{II}) ;(\mathrm{g}, \mathrm{h}, \mathrm{i}) V_{s l}=0.74 \mathrm{~m} / \mathrm{s}, V_{s g}=0.81 \mathrm{~m} / \mathrm{s}(\mathrm{SS}-\mathrm{III})$.

\subsubsection{Transitional severe slugging (SST)}

This is a transitional flow regime between severe slugging and stable flow. The major difference between transitional severe and severe slugging is that the dominant pressure difference over the riser is smaller for SST, thus, the slug length is less than one riser length. Three types of transitional severe slugging were identified in this study: SST-I, SST-II and OSC.

Transitional severe slug type I (SST-I): This tends to occur at higher gas and lower liquid flow rates. The pressure difference over the riser (Fig.5a) shows multiple gas penetration between two proportionately larger differential pressure leaps. The characteristics of SST-I are quite similar to those of SS-III, but with frequent gas penetration at the riser base and smaller pressure fluctuations. The PDF (Fig.5b) has a two-peak distribution, the higher peak occurs at higher pressure whereas the lower peak occurs at a lower pressure. The PSD (Fig.5c) has multiple peaks and a major peak with strong dominant frequency and PSD amplitudes smaller than those of SS-I, SS-II and SS-III.

Transitional severe slug type II (SST-II): This is observed at higher liquid and lower gas flow rates. The pressure difference over the riser (Fig.5d) shows more frequent gas penetration at the riser base and multiple smaller and larger differential pressure leaps. The PDF (Fig.5e) shows a Gaussian-like distribution that is spread out almost evenly. The PSD (Fig.5f) has multiple components that spread throughout the frequency domain and the highest peak occurs at a lower frequency than that of SST-I.

Oscillation flow (OSC): This transitional severe slug exists at higher gas flow rates than SST-II. The pressure difference over the riser (Fig.5g) shows frequent cyclic pressure fluctuations without the spontaneous vigorous blowdown. The PDF (Fig.5h) shows a flatten peak and the distribution spread out over higher pressures. The PSD 
(Fig.5i) has multiple high and low peaks spread throughout the frequency domain with the dominant frequency peak occurring at a higher frequency when compared to SST-II.
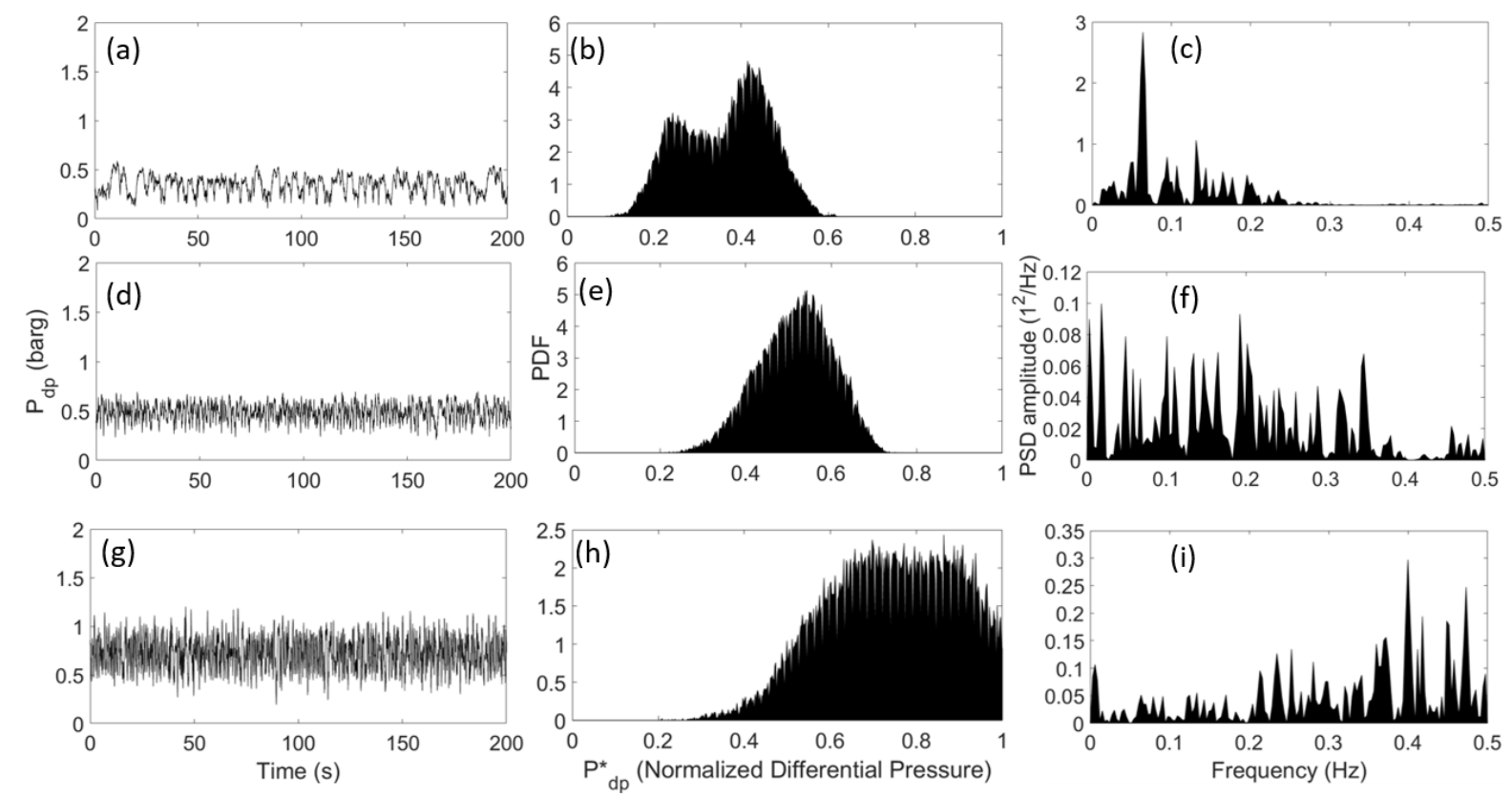

Fig. 5. Differential pressure over the riser (time series), PDF and PSD of the differential pressure over the riser during different types of transitional severe slugging flow (a,b,c) $V_{s l}=0.51 \mathrm{~m} / \mathrm{s}, V_{s g}=5.21 \mathrm{~m} / \mathrm{s}(\mathrm{SST}-\mathrm{I})$; (d,e,f) $V_{s l}=0.99 \mathrm{~m} / \mathrm{s}, V_{s g}=4.71 \mathrm{~m} / \mathrm{s}(\mathrm{SST}-\mathrm{II}) ;(\mathrm{g}, \mathrm{h}, \mathrm{i}) V_{s l}=1.73 \mathrm{~m} / \mathrm{s}, V_{s g}=8.08 \mathrm{~m} / \mathrm{s}(\mathrm{OSC})$.

\subsubsection{Stable flow (STB)}

Stable flow was generally observed at relatively high gas flow and liquid flow rates, and it has the lowest pressure amplitudes. Its pressure trend over the riser profile remains roughly constant with smaller fluctuation, and the gas and liquid flow continuously into the riser without complete blockage of the pipeline. Four types of stable flow were identified in this study: bubble, slug, churn, and annular.

Bubble flow: This is manifest when the gas and liquid continuously flow through the riser with very small deviations as shown in Fig.6a. It appears as a continuum of liquid with dispersed gas bubbles. The PDF (Fig.6b) shows a single peak with the highest normalised differential pressure when compared to other flow regimes in the stable category. The PSD (Fig.6c) has multiple peaks, and two peaks with dominant frequencies. The highest peak occurs at a lower frequency when compared to the other with dominant frequency and has PSD amplitude higher than the rest in the frequency distribution.

Slug flow: This fluctuates more frequently and has a smaller amplitude than SST-I, SST-II and OSC as can be seen in Fig.6d. This is evident with the intermittent nature of the liquid slug, and it exhibits the largest pressure fluctuation amongst all the stable flow regimes. The PDF (Fig.6e) shows a Gaussian-like distribution that is spread out almost evenly at higher normalised differential pressure, it has the second highest normalised differential pressure when compared to other flow regimes in the stable category. The PSD (Fig.6f) has multiple components 
spread throughout the frequency domain. It has two peaks with dominant frequencies, the major peak has a higher and stronger dominant frequency. This major peak occurs at a frequency higher than that of bubble flow.

Churn flow: This flow regime appears at a high gas flow rate and low liquid flow rate. It exhibits smaller amplitudes and fluctuates more frequently than the slug flow as shown in Fig.6g. The PDF (Fig.6h) also exhibits a Gaussian-like distribution that is spread out almost evenly, however, it occurs at a lower normalised differential when compared to slug flow. The PSD (Fig.6i) has multiple high and low peaks spread throughout the frequency domain. It has multiple peaks with dominant frequencies.

Annular flow: This is manifest at higher gas flow rate and low liquid flow rates. Annular flow fluctuates at very high frequency and exhibits very small amplitudes as shown in Fig.6j. The PDF (Fig.6k) shows a single peak that occurs at the lowest normalised differential pressure when compared to other flow regimes in the stable category. The PSD (Fig.61) has two major peaks with dominant frequency and other smaller multiple components in the frequency domain. The largest peak occurs at a lower frequency and exhibits the strongest dominant frequency.
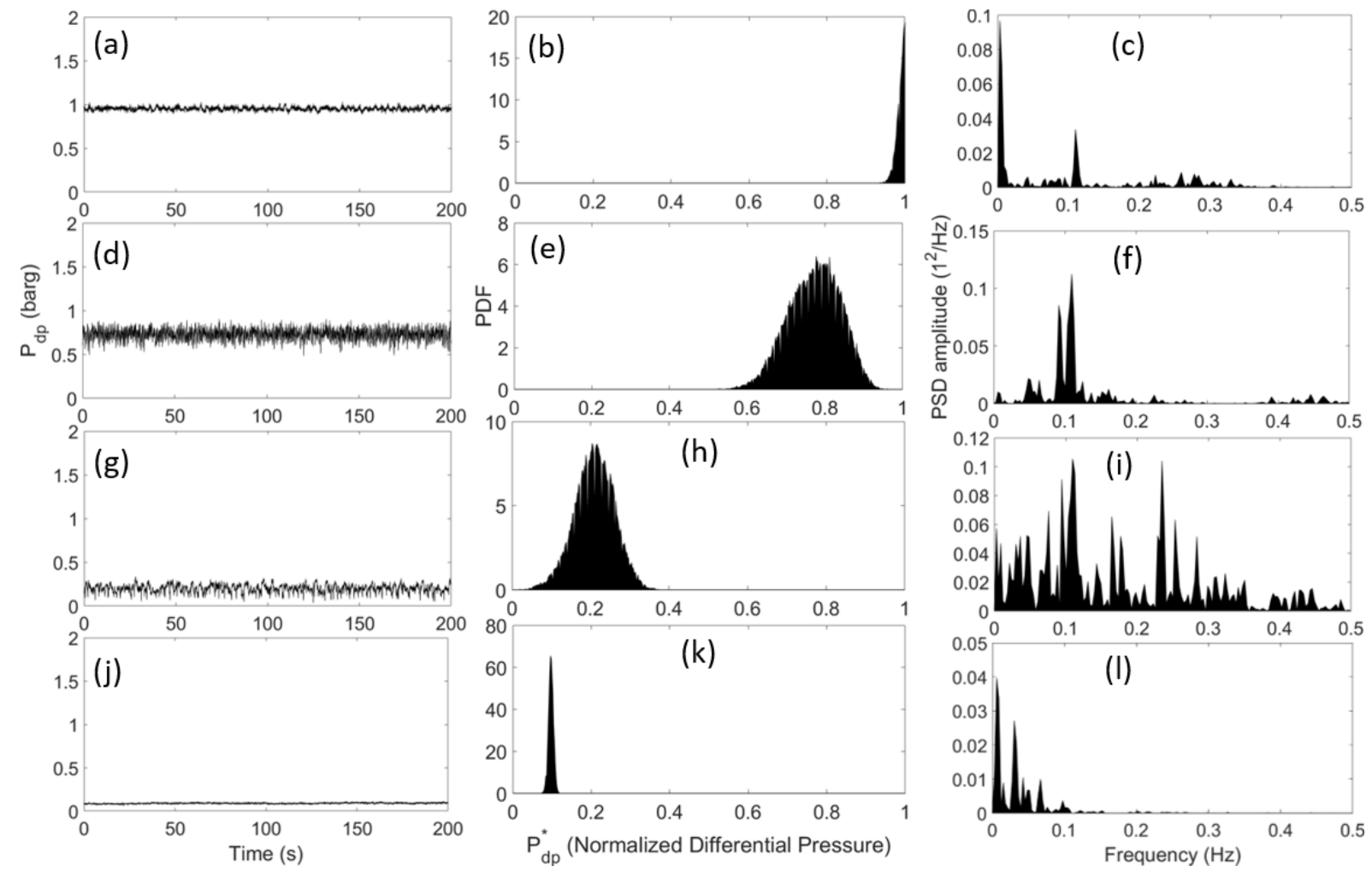

Fig. 6. Differential pressure over the riser (time series), PDF and PSD of the differential pressure over the riser during different types of stable flow (a,b,c) $V_{s l}=1.73 \mathrm{~m} / \mathrm{s}, V_{s g}=0.36 \mathrm{~m} / \mathrm{s}$ (Bubble flow); (d,e,f) $V_{s l}=2.55 \mathrm{~m} / \mathrm{s}$, $V_{s g}=2.44 \mathrm{~m} / \mathrm{s}$ (Slug flow); (g,h,i) $V_{s l}=0.25 \mathrm{~m} / \mathrm{s}, V_{s g}=13.84 \mathrm{~m} / \mathrm{s}$ (Churn flow); (j,k,l) $V_{s l}=0.05 \mathrm{~m} / \mathrm{s}, V_{s g}=$ $18.88 \mathrm{~m} / \mathrm{s}$ (Annular flow).

\subsection{Flow pattern map}

The experimental data was used to generate flow pattern maps in order to obtain an overview of the different flow pattern within the test matrix. The flow pattern map for the pipeline-riser without the injectable venturi is 
shown in Fig.7. The figure shows ten flow patterns which are present in the test matrix. These were further broadly classified as severe slugging, transitional severe slugging and stable flow.

The test points within the test matrix were converted to their respective superficial liquid and gas velocities and were used as coordinates to indicate the distribution of each flow pattern. The flow pattern regions obtained in this study are consistent with Tin's (1991) steep S-shape riser flow pattern map as shown in Fig.7. However, the range for each region is different due to the difference in test loops. In his study, Tin (1991) categorised his flow pattern map as severe slugging 1 , severe slugging $1 \mathrm{~b}$, transition, oscillation and stable flow.

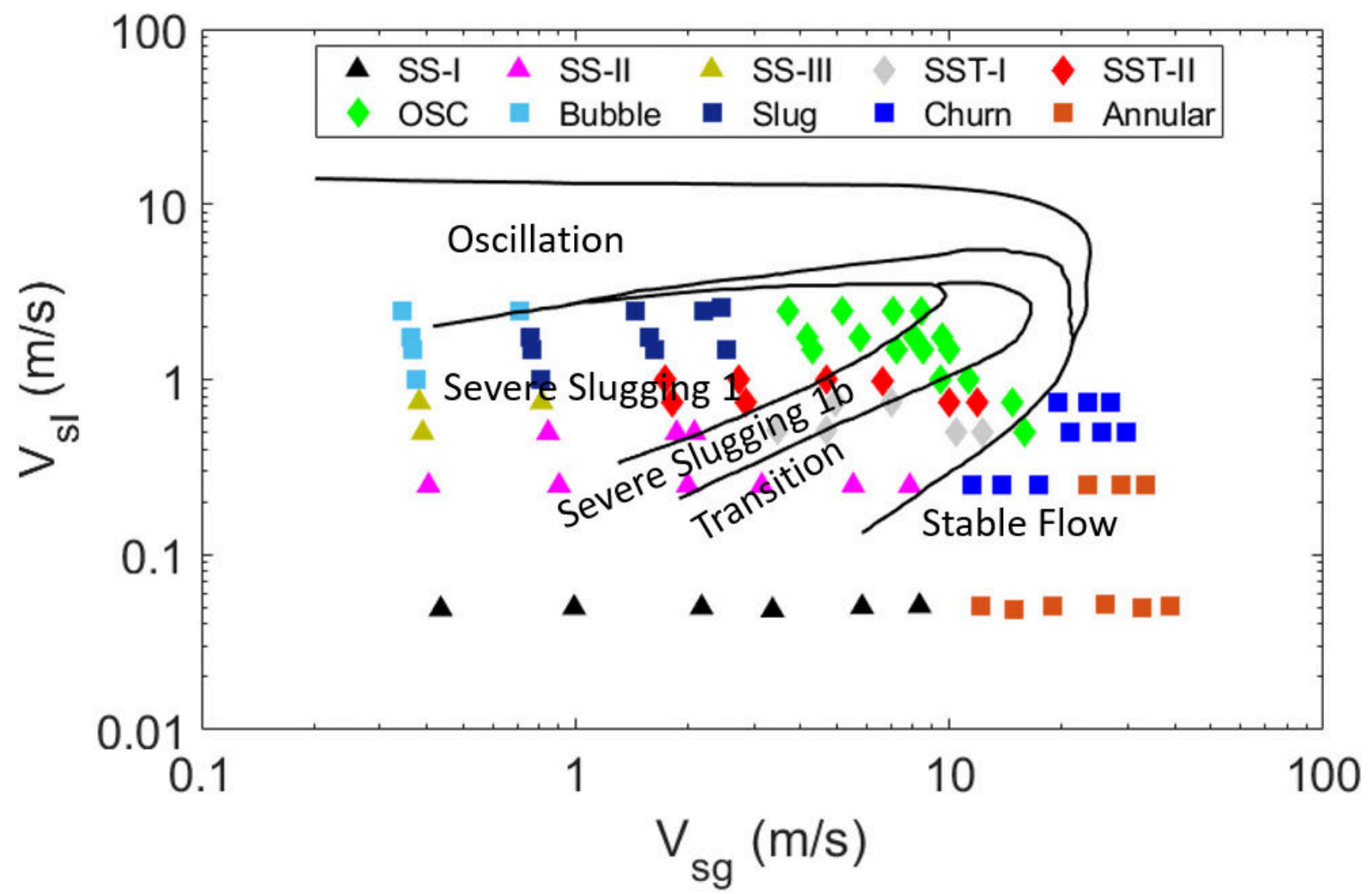

Fig. 7. Flow pattern map for the plain riser compared with steep S-shape riser flow regime map by Tin (1991)

\subsection{Effects of injectable venturi on flow in the pipeline-riser system}

The effects of the injectable venturi on the flow behaviour in pipeline-riser systems were studied. Similar techniques used in developing the flow regime map for the pipeline-riser without the injectable venturi were applied to develop the flow pattern map for the pipeline-riser with the venturi and the injectable venturi applied. Fig.8, Fig.9 and Fig.10 show the flow pattern maps for the plain riser, and with the venturi, and the injectable venturi applied respectively. 


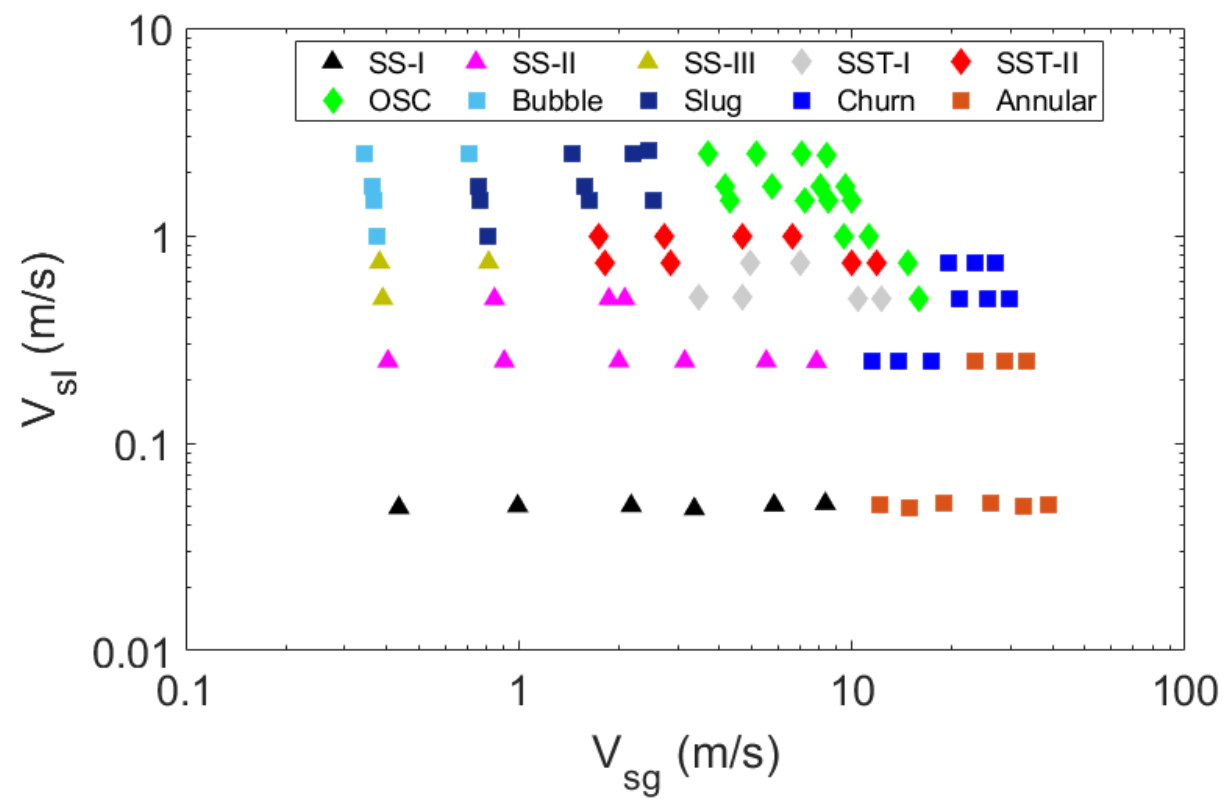

Fig. 8. Flow pattern map for the plain riser

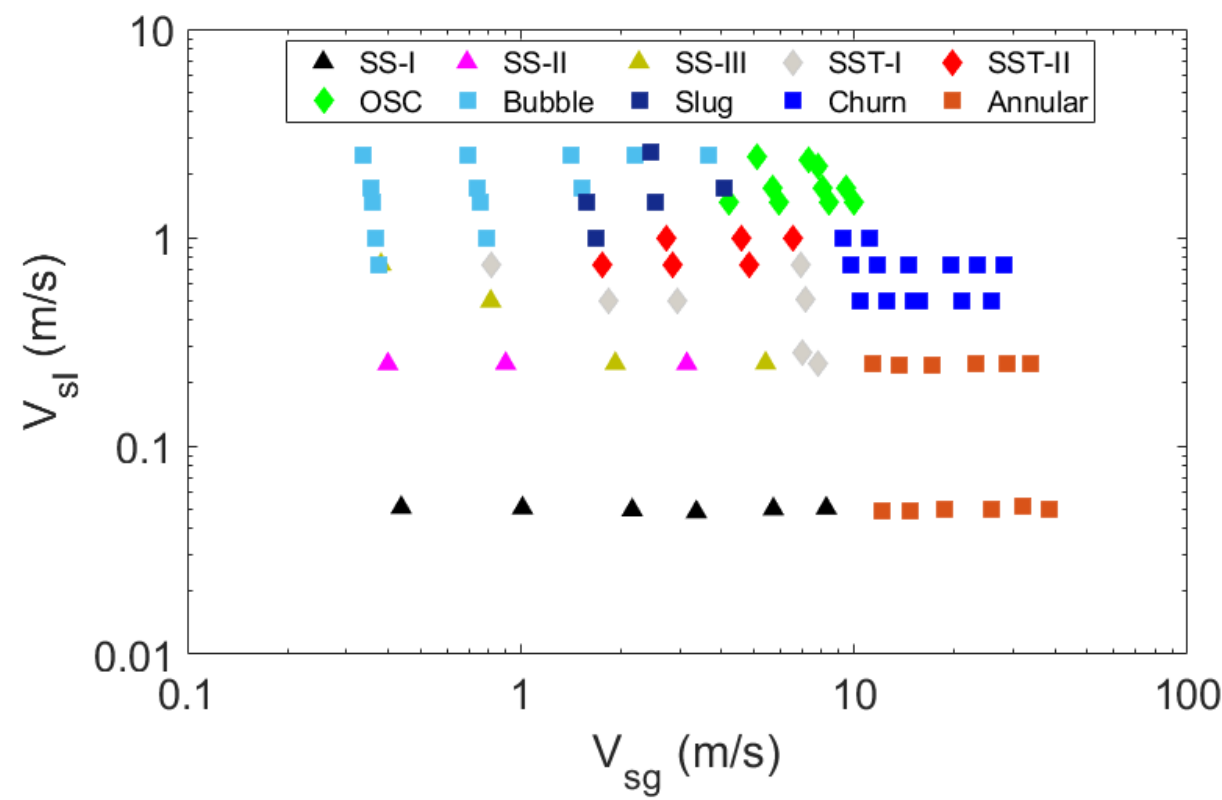

Fig. 9. Flow pattern map for the riser with injectable venturi with no gas injection applied 


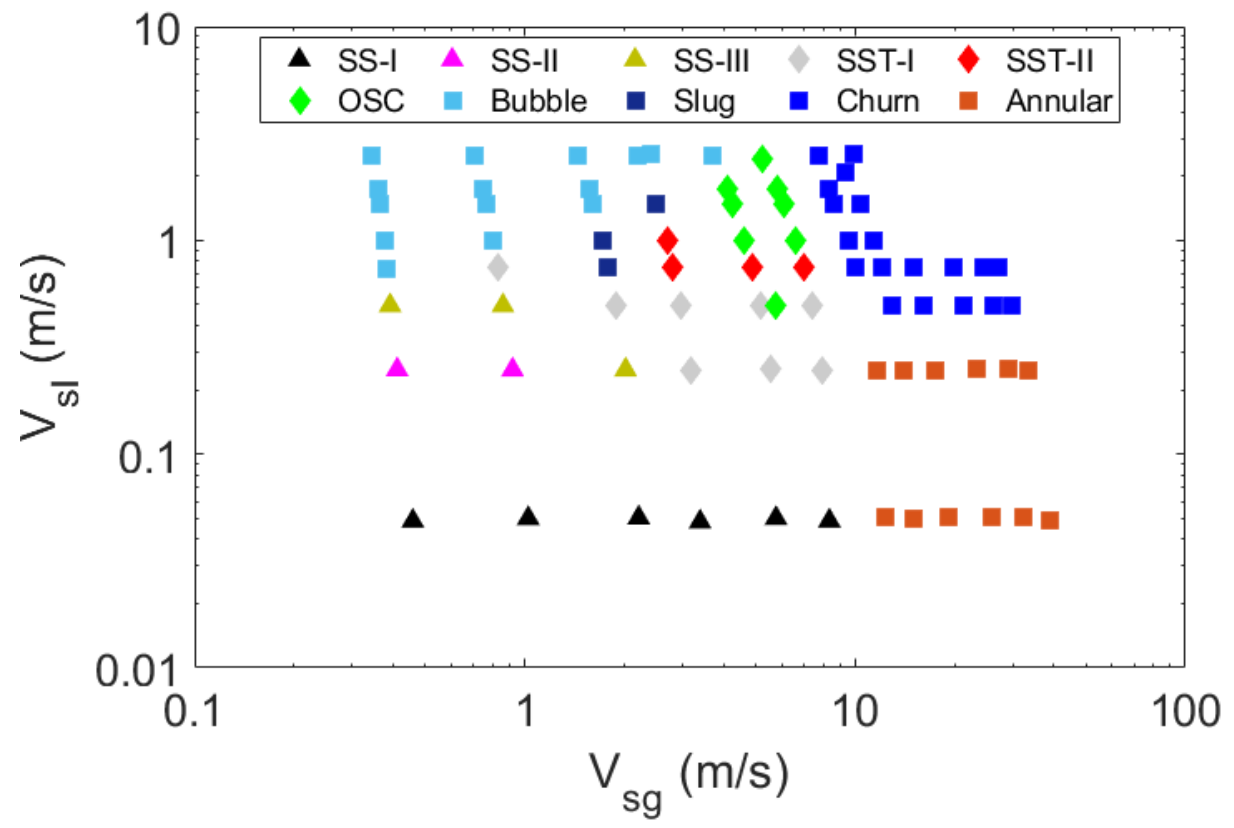

Fig. 10. Flow pattern map for the riser with injectable venturi with gas injection applied

Comparing Fig.8, Fig.9 and Fig.10 it can be seen that previously severe slugging and transitional severe slugging test points have been converted to stable ones. In addition, the severity of severe slugging and transitional severe slugging have been reduced as some test points have been converted from SS-I to SS-II, SS-II to SS-III, SST-I to SST-II and SST-II to OSC. Furthermore, some stable flow regimes have been converted to more stable ones (e.g. slug to bubble and churn to annular). Venturi produces less permanent pressure losses and high-pressure recovery, hence, it saves energy. The gradual flowing area expansion (diverging section) of the venturi helps in accelerating the two-phase flow in the pipeline-riser. Thus, breaking down severe slugging, reducing its severity and in some instances converting them to stable flow. On the other hand, some stable flows were converted to more stable ones. These explains why the performance of the injectable venturi with no gas injection is better than that of the plain riser. However, the injectable venturi with gas injection map (Fig. 10) gave a better performance in terms of improving the stability in the pipeline-riser since it enhances the performance of the venturi (injectable venturi with no gas injection). Thus, the application of the injectable venturi with and with no gas injection reduced the severity of severe slugging in some test points. It also eliminated severe slugging in some test points, as we can see that some of these test points were converted to stable flow. However, the injectable venturi with gas injection had the best performance when compared to the injectable venturi with no gas injection. This implies that severe slugging can be eliminated and the severity of severe slugging can be reduced by applying injectable venturi to pipeline-riser systems. This practically translates to an improvement to the stability of the system, thus, enhancement of flow assurance.

\subsection{Severe slug envelopes}

Stability map was generated to further demonstrate the severe slug attenuation benefits of the injectable venturi coupled to the pipeline-riser system. This map was generated by grouping severe slugging and transitional severe 
slugging from the flow pattern maps and re-categorising them as severe slugging. The stable flow remains as it was previously defined in Sections 4.1 and 4.1.3. Thus, the stability map is divided into two regions: unstable (severe slugging) and stable (stable flow). Fig.11 shows the combined stability map for the plain riser, the injectable venturi with and no injection. The envelopes were created by tracing the stability boundaries (outer severe slugging data points) for each case. These envelopes were used as a yardstick to measure, demonstrate and compare the severe slug elimination performance of the pipeline-riser with the injectable venturi applied.

It can be seen that the severe slug envelope of the injectable venturi with gas injection is the smallest followed by that of the injectable venturi with no gas injection when compared to that the plain riser. Thus, the coupling of the injectable venturi with no gas injection to the pipeline-riser system has led to a reduction of the severe slugging operating region within the test matrix. However, the coupling of the injectable venturi with gas has led to a further reduction of the severe slugging operating region within the test matrix. In addition, more severe slugging test points were eliminated and converted to stable ones. These test points would have required choking the topside choke valve to be converted to stable flow. This would require a reduction in choke valve opening. However, with the injectable venturi applied the choke valve will be fully (100\%) open at those test points. This practically implies that oil and gas production may be increased. Additionally, it implies an improvement to the stability of the system, thus, enhancement of flow assurance.

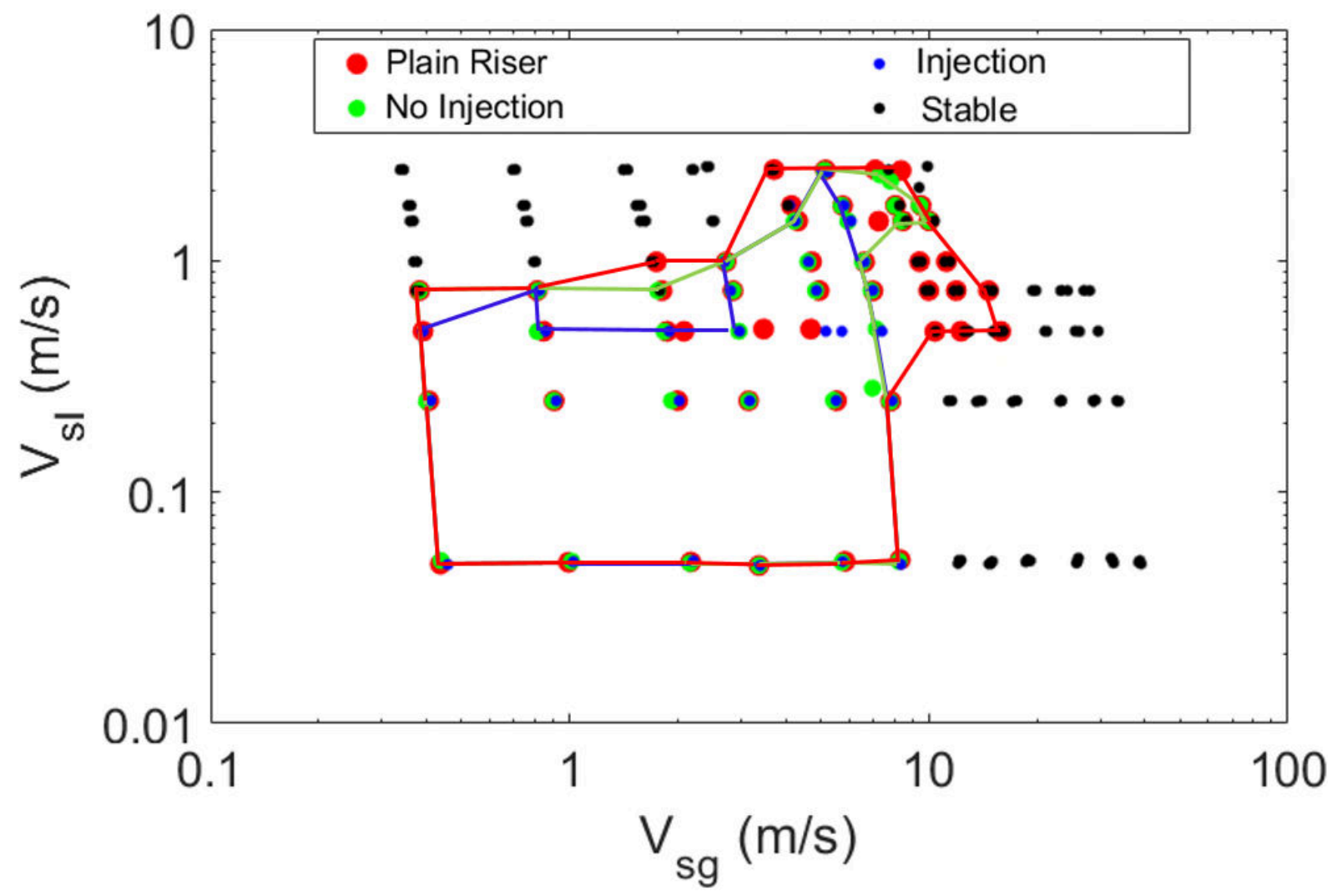

Fig. 11. Severe slug envelops for the pipeline-riser with and without the injectable venturi 


\subsection{Stability study}

Having established the effects of injectable venturi with gas injection on flow in a pipeline riser system, there was a need to ascertain if its severe slug mitigation capability is due to the venturi itself or due to injection. In other words, whether the gas injection enhances severe slug mitigation capability or not. Thus, stability studies were carried out for the plain riser, injectable venturi with no injection and with injection.

Hopf bifurcation and the traditional choking techniques were combined and used for the study. The study was conducted on a severe slugging condition of $V_{s l}=0.25 \mathrm{~m} / \mathrm{s}$ and $V_{s g}=3.1 \mathrm{~m} / \mathrm{s}$ for water and air respectively. Fig. 12(a) shows the riser base pressure bifurcation map for the plain riser. It was observed that as the pipeline-riser system is choked by reducing the valve opening the back pressure increases, the severity of slugging was reduced and the flow condition changed from severe slugging to stable flow. Bifurcation (critical valve opening) occurred at $21 \%$ valve opening and average riser base pressure value of $2.7 \mathrm{barg}$. A similar procedure was used to develop the riser base pressure bifurcation map for the severe slugging condition investigated for the injectable venturi with no injection as shown in Fig. 12(b). Bifurcation occurred at a larger valve opening of $23 \%$ and a lower average riser base pressure value of $2.5 \mathrm{barg}$. The low loss of energy is due to the gradual change in geometry of the injectable venturi. This may account for its ability to achieve stability at a lower riser base pressure.

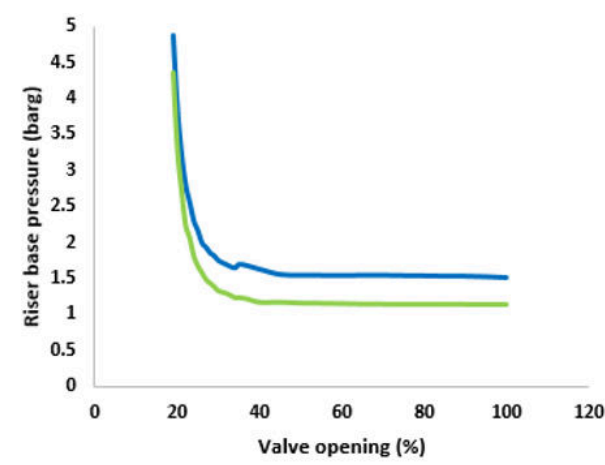

(a)

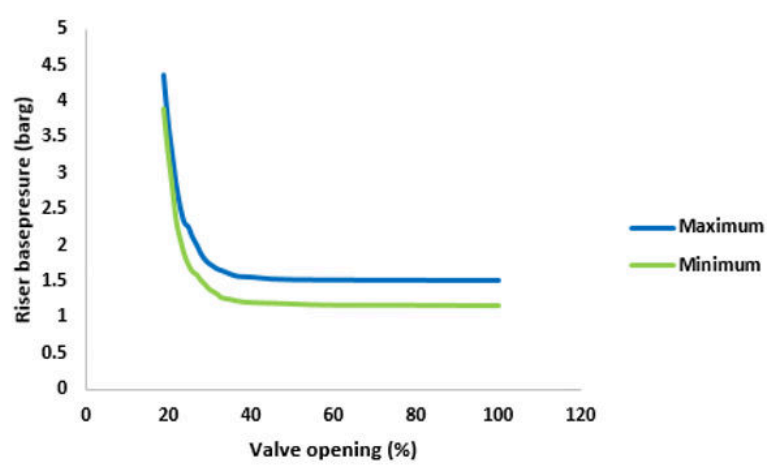

(b)

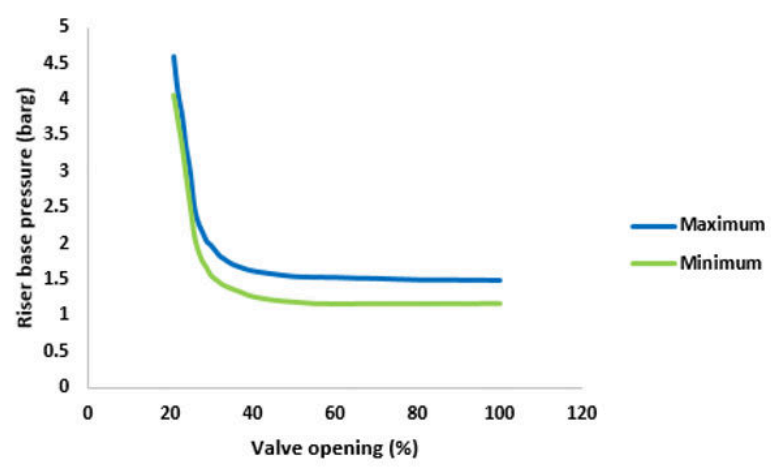

(c)

Fig. 12. Riser base bifurcation map at $\boldsymbol{V}_{\boldsymbol{s l}}=0.25 \mathrm{~m} / \mathrm{s}$ and $\boldsymbol{V}_{\boldsymbol{s} \boldsymbol{g}}=3.1 \mathrm{~m} / \mathrm{s}$ for (a) plain riser (b) injectable venturi with no injection (c) injectable venturi with injection 
Fig. 12(c) shows the riser base pressure bifurcation map for the injectable venturi with gas injection. Similarly, bifurcation occurred at a larger valve opening and a lower average riser base pressure as with the no injection case. However, it occurred at a valve opening of $27 \%$ and average riser base pressure value of 2.3 barg which are higher and lower than that of no injection case respectively. Thus, comparing Fig. 12(a) and Fig. 12(b), there was a $17.4 \%$ increase in valve opening and an $8 \%$ reduction in the riser base pressure. This proves that the performance of the injectable venturi is not due to the venturi itself but due to the gas injected into the venturi. Similarly, comparing Fig. 12(b) and Fig. 12(c), there was a $29 \%$ increase in valve opening and a $15 \%$ reduction in the riser base pressure. This reduction in the riser base pressure achieved by coupling the injectable venturi to the pipeline-riser system leads to an increase in production. Reservoirs are often considered to have reached the end of their useful life sometime before they are actually exhausted due to low pressures which give rise to severe slugging. This result suggests that the operational life of a reservoir might be extended by adopting this technique. Hence, oil recovery in brown fields would be enhanced. Also, the result shows that injecting gas at the throat of the venturi improves the performance of the conventional venturi. Practically, these imply an improvement to the stability of the system and increase in oil and gas production.

\subsection{Discussion}

Flow conditioners are simple, and they mostly do not cause problems for pigging operations. However, the major drawback for this method is the very expensive installation cost and maintenance due to subsea deployment. An intermittent absorber is cheap and simple to install since it does not require subsea deployment. However, designing and seizing an appropriate intermittent absorber that will achieve optimum slug attenuation or elimination is difficult. In addition, it will be difficult for an intermittent absorber to accommodate large slugs or variations in flow. The multiple risers method is viable since it does not impose back pressure on the system. The main idea here is to avoid having multiphase flow completely in the pipeline riser in order to avoid severe slugging. However, it is not economical as it will significantly increase CAPEX and OPEX (Operational Expenditure) due to design changes, subsea deployment, the requirement of multiple single-phase pipelines and increase in the frequency of pigging operations.

Slug catchers (deployed at the top of the well or just before the processing system) are very good at mitigating severe slug. However, due to space and weight limitations at platforms, it is very expensive to implement. In addition, it is not able to deal with all slug sizes due to its limited buffer volume. Furthermore, determination of the actual slug catcher size that will accommodate all slugs and optimise the process is also complicated and a serious challenge. Permanent choking is one of the effective approaches to eliminate severe slugging in oil and gas production systems. However, due to the non-linearity of multiphase flow, fixed choking will be ineffective during sudden changes or variations in fluid velocities, which could either make the system stable or unstable. In addition, it does not provide an optimal solution in terms of production optimisation even if the valve is choked to the optimal point (open-loop bifurcation point).

It has been demonstrated experimentally that the injectable venturi is a viable and effective method for severe slugging mitigation. It is a cheaper option when compared to other methods that require expensive installation 
and maintenance which will significantly increase CAPEX and OPEX. In addition, its installation at the topside is an additional advantage when compared with other methods that require subsea installation. Furthermore, it has been demonstrated that the injectable venturi with gas injection has the potential of increasing production and enhancing recovery. However, the effects of controllers on the performance of the injectable venturi need to be investigated.

\section{Conclusions}

The performance of the injectable venturi on severe slugging mitigation has been presented. It was studied and compared with that of the plain pipeline-riser in terms of flow regime maps, severe slug envelopes and Hopf bifurcation maps. The flow regimes in the pipeline-riser system have been objectively categorised into ten flow regimes. The working principle of the injectable venturi has been presented. Experimental evidence from the study shows that:

- The pipeline-riser system can be stabilised with the application of an injectable venturi

- The effectiveness of the injectable venturi is not due to the venturi itself, but due to gas injection at the throat of the venturi

- An injectable venturi is effective in mitigating severe slugging

- The severity of severe slugging was reduced in some test points, thus, an injectable venturi can be used to reduce the severity of slugging in a pipeline-riser system

- Severe slugging was completely eliminated in some test point within the test matrix, thus, injectable venturi can be used to eliminate severe slugging in a pipeline-riser system

- Severe slug operating region can be reduced by applying an injectable venturi to the pipeline-riser system

- An injectable venturi coupled to a pipeline-riser can stabilise flow at a larger valve opening and a lower pressure when compared to the plain pipeline-riser. This practically implies an increase in oil and gas production.

This is an economical severe slug mitigation method, its installation at the topside is an additional advantage when compared with other methods that require subsea deployment. The increase in brown fields due to diminishing reserves of oil from reservoirs have made oil recovery very vital. Reservoirs are often considered to have reached the end of their useful life sometime before they are actually exhausted due to low pressures. Thus, this technique potentially will help to extend the operational life of a reservoir, thus enhancing oil recovery and flow assurance.

The potential impact of the findings of this study would go a long way in helping the oil and gas industries in areas such as: production management, well testing, reservoir management and custody transfer. Further work is needed to ascertain if its performance could be improved with the application of controllers. 


\section{Acknowledgements}

The authors would like to express sincere thanks to Petroleum Technology Development Fund (PTDF), for sponsoring Joseph Inok's research.

\section{References}

Abbagoni, B. M. and Yeung, H. (2016) 'Non-invasive classification of gas - liquid two-phase horizontal flow regimes using an ultrasonic Doppler sensor and a neural network', Measurement Science and Technology. IOP Publishing, 27. doi: 10.1088/0957-0233/27/8/084002.

Adedigba, A. G., Badr, O., Yeung, H., Waring, R. and Caro, C. (2006) 'The use of novel pipe device to reduce severe slugging in pipeline-riser systems', in Proceedings of 5th North American Conference on Multiphase Technology. Banff, Canada, 31 May- 2 June: BHR Group.

Adedigba, A. G. (2007) Two-phase flow of gas-liquid mixtures in horizontal helical pipes. Cranfield University.

Almeida, A. R. D. and Gonçalves, M. D. A. L. (1999) 'Venturi for severe slug elimination', in Proceedings of 9th International Conference on Multiphase Production, BHRG. Bury St. Edmunds; Professional Engineering Publishing, pp. 149-158.

Almeida, A. R. De and Gonçalves, M. D. A. L. (2000) 'Device and Method for Eliminating Severe Slugging in Multiphase-Stream Flow Lines'. USA.

Baliño, J. L., Burr, K. P. and Nemoto, R. H. (2010) 'Modeling and simulation of severe slugging in air-water pipeline-riser systems', International Journal of Multiphase Flow, 36(8), pp. 643-660. doi: 10.1016/j.ijmultiphaseflow.2010.04.003.

Brasjen, B. J., Hansen, J. H., Schiferli, W. and Belfroid, S. P. C. (2013) 'Experimental investigation of terrain slugging formation, evolution and potential mitigation', in Proceedings of 16th International Conference on Multiphase Production Technology, , 12-14 June, Cannes, France, BHR Group, pp. 1-9.

Ehinmowo, A. B., Orodu, O. D., Anawe, P. A. L. and Ogunleye, O. O. (2016) 'Attenuating severe slug flow at large valve opening for increased oil production without feedback control signal', Journal of Petroleum Science and Engineering. $\quad$ Elsevier, 146, pp. 1130-1141. doi: http://www.sciencedirect.com/science/article/pii/S0920410516303321.

Farghaly, M. A. (1987) 'Study of Severe Slugging in Real Offshore Pipeline Riser-Pipe System', in Middle East Oil Show. Society of Petroleum Engineers. doi: 10.2118/15726-MS.

Godhavn, J. M., Fard, M. P. and Fuchs, P. H. (2005) 'New slug control strategies, tuning rules and experimental results', Journal of Process Control, 15(5), pp. 547-557. doi: 10.1016/j.jprocont.2004.10.003. $1-16$.

Havre, K. and Dalsmo, M. (2001) 'Active Feedback Control as the Solution to Severe Slugging', in Proc, pp.

Havre, K., Stornes, K. O. and Stray, H. (2000) 'Taming slug flow in pipelines', ABB Review, 4, pp. 55-63.

Henriot, V., Courbot, A., Henintzé, E. and Moyeux, L. (1999) 'Simulation of Process to Control Severe Slugging: Application to the Dunbar Pipeline', SPE Annual Technical Conference and Exhibilion, (SPE 56461), pp. 171-179. doi: 10.2118/56461-ms.

Hill, T. J. (1989) 'Riser Base Gas Injection into the S.E Forties Line', in Proceedings of 4th International Conference on Multiphase Flow, BHRG. Nice, France, pp. 133-148. 
Hill, T. J. (1990) 'Gas injection at riser base solves slugging, flow problems', Oil and Gas Journal. Nice, France, 26(3), pp. 88-92.

Jansen, F. E., Shoham, O. and Taitel, Y. (1996) 'The elimination of severe slugging - Experiments and modeling', International Journal of Multiphase Flow, 22(6), pp. 1055-1072. doi: 10.1016/0301-9322(96)000274.

Kaasa, O. (1990) 'A sub-sea slug catcher to prevent severe slugging', in Proceedings of the Underwater Technical Conference, Bergen, Norway, p. 387.

Li, N., Guo, L. and Li, W. (2013) 'Gas-liquid two-phase flow patterns in a pipeline-riser system with an Sshaped riser', International Journal of Multiphase Flow. Elsevier Ltd, 55, pp. 1-10. doi: 10.1016/j.ijmultiphaseflow.2013.04.003.

Li, W., Guo, L. and Xie, X. (2017) 'Effects of a long pipeline on severe slugging in an S-shaped riser', Chemical Engineering Science, 171, pp. 379-390. doi: 10.1016/j.ces.2017.05.017.

Malekzadeh, R. (2012) Severe slugging in gas-liquid two-phase pipe flow. PhD Thesis, De Technische Universiteit Delft.

Malekzadeh, R., Henkes, R. A. W. M. and Mudde, R. F. (2012) 'Severe slugging in a long pipeline-riser system: Experiments and predictions', International Journal of Multiphase Flow. Elsevier Ltd, 46, pp. 9-21. doi: 10.1016/j.ijmultiphaseflow.2012.06.004.

Matsui, G. (1984) 'Identification of flow regimes in vertical gas-liquid two-phase flow using differential pressure fluctuations', International Journal of Multiphase Flow, 10(6), pp. 711-719. doi: 10.1016/03019322(84)90007-7.

Matsui, G. (1986) 'Automatic Identification of Flow Regimes in Vertical Two-Phase Flow using Differential Pressure Fluctuations', Nuclear Engineering and Design, 95, pp. 221-231.

Matsumoto, S. and Suzuki, M. (1984) 'Statistical analysis of fluctuations of froth pressure on perforated plates without downcomers', International Journal of Multiphase Flow, 10, p. 217.

McGuinness, M. and Cooke, D. (1993) 'Partial Stabilisation at St. Joseph', Proceedings of the Third International Offshore and Polar Engineering Conference, June 6-11, Singapore, 2(June), pp. 235-241.

Di Meglio, F., Kaasa, G. O., Petit, N. and Alstad, V. (2012) 'Model-based control of slugging: Advances and challenges', IFAC Proceedings Volumes (IFAC-PapersOnline). IFAC, 1(PART 1), pp. 109-115. doi: 10.3182/20120531-2-NO-4020.00029.

Di Meglio, F., Kaasa, G., Petit, N. and Alstad, V. (2010) 'Model-based control of slugging flow: an experimental case study', American Control Conference (ACC), 1, pp. 2995-3002. doi: 10.1109/ACC.2010.5531271.

Montgomery, J. A. (2002) Severe slugging and unstable flows in an S-shaped riser. PhD Thesis, Cranfield University, Bedfordshire UK.

Montgomery, J. A. and Yeung, H. C. (2002) 'The Stability of Fluid Production From a Flexible Riser', Journal of Energy Resources Technology, 124(2), p. 83. doi: 10.1115/1.1467646.

Ogazi, A., Cao, Y., Yeung, H. and Lao, L. (2010) 'Slug Control With Large Valve Openings To Maximize Oil Production', SPE Journal, 15(3), pp. 812-821. doi: 10.2118/124883-PA.

Ogazi, A. I., Ogunkolade, S. O., Cao, Y., Lao, L. and Yeung, H. (2009) 'Severe Slugging Control Through Open Loop Unstable Pid Tuning To Increase Oil Production', Proceedings of 14th International Conference on Multiphase Technology, Cannes, France, pp. 17-32.

Park, S. and Nydal, O. J. (2014) 'Study on Severe Slugging in an S-Shaped Riser: Small-Scale Experiments 
Compared With Simulations', Oil and Gas Facilities, 3(04), pp. 72-80. doi: 10.2118/171559-PA.

Prickaerts, P., Haandrikman, G. and Henkes, R. (2013) 'Two-phase flow behaviour for a single flowline with a non-symmetric splitter to a dual riser', Proceedings of 16th International Conference on Multiphase Production Technology, pp. 471-484.

Schmidt, Z, Doty, R. D, Dutta-Roy, K. (1985) 'Severe Slugging in Offshore Production Systems', Society of Petroleum Engineers, $\quad$ (February), $\quad$ pp. $1-12 . \quad$ Available at: http://books.google.com.br/books?id=brIbQwAACAAJ.

Schmidt, Z., Brill, J. and Beggs, H. (1979) 'Choking can eliminate severe pipeline slugging', Oil and Gas Journal, 12, pp. 230-238.

Schmidt, Z., Brill, J. and Beggs, H. (1980) 'Experimental Study of Severe Slugging in a Two-Phase-Flow Pipeline - Riser Pipe System', Society of Petroleum Engineers Journal, 20(05), pp. 407-414. doi: 10.2118/8306PA.

Schrama, E. and Fernandes, R. (2005) 'The bubble breaker: breaking up slug flow into dispersed bubbly flow using a passive mechanical device', Proceedings of 12th International Conference on Multiphase Production Technology, 25-27 May, Barcelona, Spain, pp. 283-296.

Shaban, H. and Tavoularis, S. (2014) 'Measurement of gas and liquid flow rates in two-phase pipe flows by the application of machine learning techniques to differential pressure signals', International Journal of Multiphase Flow, 67, pp. 106-117. doi: 10.1016/j.ijmultiphaseflow.2014.08.012.

Siahaan, H. B., Aamo, O. M. and Foss, B. A. (2005) 'Suppressing riser-based slugging in multiphase flow by state feedback', Proceedings of 44th IEEE Conference on Decision and Control, and the European Control Conference, CDC-ECC '05, 2005, pp. 452-457. doi: 10.1109/CDC.2005.1582197.

Stasiak, M. E., Pagano, D. J. and Plucenio, A. (2012) 'A new discrete slug-flow controller for production pipeline risers', IFAC Proceedings Volumes (IFAC-PapersOnline). IFAC, 1(PART 1), pp. 122-127. doi: 10.3182/20120531-2-NO-4020.00032.

Storkaas, E. and Skogestad, S. (2004) 'Cascade Control of Unstable Systems with Application to Stabilization of Slug Flow’, IFAC Proceedings Volumes, 37(1), pp. 335-340. doi: 10.1016/S1474-6670(17)38754-2.

Taitel, Y. (1986) 'Stability of severe slugging', International Journal of Multiphase Flow, 12(2), pp. $203-217$. doi: 10.1016/0301-9322(86)90026-1.

Taitel, Y., Vierkandt, S., Shoham, O. and Brill, J. P. (1990) 'Severe slugging in a riser system: experiments and modeling', International Journal of Multiphase Flow, 16(1), pp. 57-68. doi: 10.1016/0301-9322(90)90037J.

Tin, V. (1991) 'Severe slugging characteristics in flexible riser', in in Proceedings of the 5th International Conference on Multiphase Production, 16-19 June, Cannes, France, pp. 502-526.

Welch, P. D. (1967) 'The use of fast Fourier transform for the estimation of power spectra: A method based on time averaging over short, modified periodograms', IEEE Transactions on Audio and Electroacoustics, 15(2), pp. 70-73. doi: 10.1109/TAU.1967.1161901.

Xie, T., Ghiaasiaan, S. M. and Karrila, S. (2004) 'Artiÿcial neural network approach for ow regime classiÿcation in gas - liquid - ÿber ows based on frequency domain analysis of pressure signals', Chemical Engineering Science, 59, pp. 2241-2251. doi: 10.1016/j.ces.2004.02.017.

Xing, L., Yeung, H., Shen, J. and Cao, Y. (2013a) 'A new flow conditioner for mitigating severe slugging in pipeline/riser system', International Journal of Multiphase Flow, 53, pp. 1-10. doi: 10.1016/j.ijmultiphaseflow.2013.01.003.

Xing, L., Yeung, H., Shen, J. and Cao, Y. (2013b) 'Experimental study on severe slugging mitigation by applying wavy pipes', Chemical Engineering Research and Design, 91(1), pp. 18-28. doi: 
10.1016/j.cherd.2012.06.020.

Xing, L., Yeung, H., Shen, J. and Cao, Y. (2013c) 'Numerical study on mitigating severe slugging in pipeline/riser system with wavy pipe', International Journal of Multiphase Flow. Elsevier Ltd, 53, pp. 1-10. doi: 10.1016/j.ijmultiphaseflow.2013.01.003.

Ye, J. and Guo, L. (2013) 'Multiphase flow pattern recognition in pipeline-riser system by statistical feature clustering of pressure fluctuations', Chemical Engineering Science. Elsevier, 102, pp. 486-501. doi: 10.1016/j.ces.2013.08.048.

Yocum, B. T. (1973) 'Offshore Riser Slug Flow Avoidance: Mathematical Models for Design and Optimization', in SPE European Meeting. Society of Petroleum Engineers. doi: 10.2118/4312-MS. 